\title{
Characterization of Bulk-Fill Resin Composites in Terms of Physical, Chemical, Mechanical and Optical Properties and Clinical Behavior
}

\author{
Caracterización de Resina Compuesta Mono Incremental en Relación a las \\ Propiedades Físicas, Químicas, Mecánicas y Ópticas y el Comportamiento Clínico
}

\begin{abstract}
Jefferson David Melo de Matos'; Leonardo Jiro Nomura Nakano'; Guilherme da Rocha Scalzer Lopes; Marco Antonio Bottino'; John Eversong Lucena de Vasconcelos ${ }^{2}$; Ricardo Huver de Jesus ${ }^{3}$ \& Lucas Campagnaro Maciel $^{3}$
\end{abstract}

\begin{abstract}
MATOS, J. D. M.; NAKANO, L. J. N.; LOPES, G. R. S.; BOTTINO, M. A.; VASCONCELOS, J. E. L.; JESUS, R. H. \& MACIEL, L. C. Characterization of bulk-fill resin composites in terms of physical,chemical, mechanical and optical properties and clinical behavior. Int. J. Odontostomat., 15(1):226-233, 2021.

ABSTRACT: This study aims to evaluate the physical, chemical, mechanical and optical properties of Bulk-Fill resin, in relation to the literature and its proper clinical uses. A bibliographic search was performed in the main health databases PUBMED (www.pubmed.gov) and Scholar Google (www.scholar.google.com.br), in which articles published from 1994 to 2020 were collected. Laboratory studies, case reports, systematic reviews and literature reviews, which were developed in living individuals, were included. Therefore, articles that did not deal with the characteristics of the Bulk-Fill resin and its proper clinical uses were excluded. The use of Bulk-Fill resin has been progressively increasing over the years, presenting good properties, achieving success in clinical performance, ease of handling and thus has become the material of choice for dentists. In addition, its longevity demonstrates durability with mechanical properties and resistance to tooth structure. BulkFill resins have characteristics similar to traditional composite resins, when performed according the usage protocol. With the use of this group of resins in a single increment, possible failures that occur during the restorative procedure can be minimized, such as: less chance of incorporating bubbles and a volumetric contraction with less stress on the interface.
\end{abstract}

KEY WORDS: composite resins, stress, mechanical, physical properties, esthetics, dental.

\section{INTRODUCTION}

Due to the growing search for restorative dentistry for the return of the shape, function and aesthetics of teeth, numerous reasons have led to an increase in the creation of new materials (Reis et al., 2017). With the failures of acrylic resins chemically or thermally activated and epoxy resins, Composite Resins (CR) emerged in the 1960 s where they were formed by an association of silica particles treated with vinyl silane and a resin matrix of Bisphenol-Glycidyl Methacrylate (Bis-GMA). Currently, $\mathrm{CR}$ is formed by an organic, inorganic matrix and a bonding agent (Rueggeberg et al., 1994; Tauböck \& Attin, 2016; Chesterman et al., 2017).
Over the years, CRs have undergone countless transformations in order to reduce adverse characteristics. In this context, this material has undergone changes in the organic matrix related to quantity and composition; however, the dominant methacrylate matrix remained intact (Rueggeberg et al.).

Dentistry has been expanding its applications and working with new technologies to evolve dental materials. One area that has gained notoriety is Restorative Nanotechnology, as it works on a nanometer scale from 0.1 to $100 \mathrm{~nm}$. In this sense, the amount of

\footnotetext{
${ }^{1}$ Program in Restorative Dentistry, Department of Dental Materials and Prosthodontics, São Paulo State University (Unesp), Institute of Science and Technology, São José dos Campos - SP, Brazil.

${ }^{2}$ Program in Dentistry, Department of Implantology and Prosthodontics, College of Dentistry CECAPE, Juazeiro do Norte - CE, Brazil.

${ }^{3}$ Program in Dentistry, Department Prosthodontics, Faculdade Multivix, Vitória - ES, Brazil.
} 
MATOS, J. D. M.; NAKANO, L. J. N.; LOPES, G. R. S.; BOTTINO, M. A.; VASCONCELOS, J. E. L.; JESUS, R. H. \& MACIEL, L. C. Characterization of bulk-fill resin composites in terms of physical,chemical, mechanical and optical properties and clinical behavior. Int. J. Odontostomat., 15(1):226-233, 2021.

nanometric particles substantially decreases the polymerization shrinkage and provides an adequate surface roughness aspect (Lin et al., 2010). In addition, another aspect that is constantly studied is silorane, which is a reduced contraction CR, indicated in increments of less than $2.0 \mathrm{~mm}$. This characteristic is related to the maximum polymerization limit, in which it is possible to join the cavity walls, due to its low contraction, compensating for the variation factor inherent to all restorative materials (Chen et al., 2011).

One aspect that is constantly discussed is the use of diluting monomers with high molecular weights that is present in some specific resins available in the dental market, such as the Charisma Diamond of the company Heraeus Kulzer. Such resin uses a monomer called TCD-urethane that replaces the usual TEGDMA, and this change has the consequence of a significant reduction in the contraction and stress of the restorative material. Nevertheless, with the exception of resins using these substances (prepolymerized particles and TCD-urethane), almost all other low-shrinkage composite resins have less volumetric shrinkage, but the shrinkage stress generated is high (Boaro et al., 2010).

The last generation of CR are Bulk-Fill or single-fill resins, which allow the use of increments of restorative material up to $4 \mathrm{~mm}$ thick, thus presenting a lower shrinkage of volumetric polymerization, resulting in low shrinkage stress (llie \& Hickel, 2011; El-Damanhoury \& Platt, 2014).

The single-fill resins are low-viscosity resins, and the main change is their greater translucency obtained through the reduced percentage of inorganic particles (44-55\% of volume) and greater amount of organic matrix, which allows greater flow providing ease of handling, shorter application time and volumetric contraction with less stress at the interface (Labella et al., 1999; Stavridakis et al., 2005).

This study aims to evaluate the physical, chemical, mechanical and optical properties of BulkFill resin, in relation to the literature and its proper clinical uses.

\section{MATERIAL AND METHOD}

A bibliographic search was performed in the main health databases PUBMED (www.pubmed.gov) and Scholar Google (www.scholar.google.com.br), in which articles published from 1994 to 2020 were collected. Laboratory studies, case reports, systematic reviews and literature reviews, which were developed in living individuals, were included. Therefore, articles that did not deal with the characteristics of the Bulk-Fill resin and its proper clinical uses were excluded.

Through bibliographic research, 50 articles were selected, 45 articles from PUBMED (www.pubmed.gov) and 5 Scholar Google (www.scholar.google.com.br) (Fig. 1). The following terms of specific medical subjects and keywords were used: Composite Resins; (DeCS / MeSH Terms), Stress, Mechanical (DeCS / MeSH Terms), Physical Properties (DeCS / MeSH Terms); Esthetics, Dental (DeCS / MeSH Terms).

According to Table I, it can be seen that the average publication of articles in the period from 1994 to 2020 from the Pubmed database was 3.21 and with a standard deviation of 2.71. While at Scholar Google, the average was 0.35 and the standard deviation 0.84 . Thus, it is possible to verify that there was a significant variation in the number of articles, in both databases.

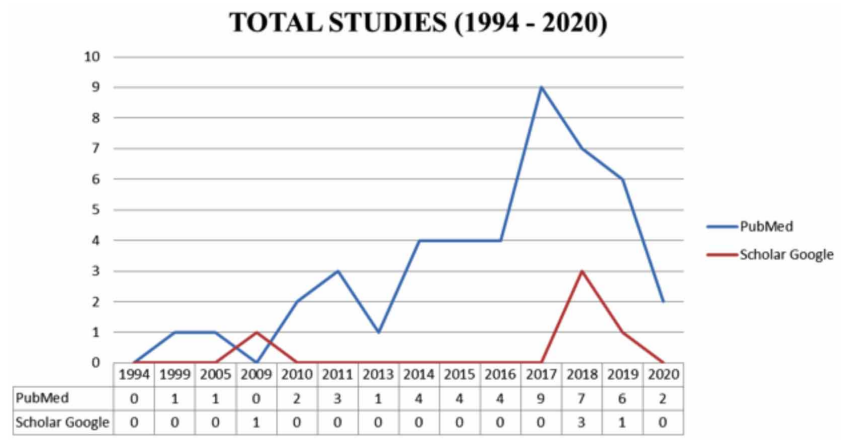

Fig. 1. Distributive graph of the total number of articles published from 1994 to 2020, in the PubMed and Google Scholar databases.

Table I. Mean \pm standard deviation of the number of studies in the main health databases.

\begin{tabular}{lcc}
\hline Database & Mean \pm Stardard Deviation & Total Studies (1994-2020) \\
\hline Pubmed & $3.21 \pm 2.71$ & 45 \\
Google Scholar & $0.35 \pm 0.84$ & 5
\end{tabular}


MATOS, J. D. M.; NAKANO, L. J. N.; LOPES, G. R. S.; BOTTINO, M. A.; VASCONCELOS, J. E. L.; JESUS, R. H. \& MACIEL, L. C. Characterization of bulk-fill resin composites in terms of physical,chemical, mechanical and optical properties and clinical behavior. Int. J. Odontostomat., 15(1):226-233, 2021.

Literature Review. The use of Bulk-Fill resin has been progressively increasing over the years, presenting good properties, achieving success in clinical performance, ease of handling and thus has become the material of choice for dentists. In addition, its longevity demonstrates durability with mechanical properties and resistance to tooth structure.

Strength. Bulk-Fill resin presents excellent conditions of use, which may be related to possible photoinitiators that increase the translucency of the material, thus allowing a greater passage of light, modifications in the inorganic phase, good viscosity of the material which provides a better marginal adaptation, allowing restorations with greater resistance (Nascimento et al., 2019).

The restoration process of deep dental cavities and the request for greater speed, encouraged the development and commercialization of a new class of resin-based materials, these materials allow a homogeneous increment in a thickness of up to $5 \mathrm{~mm}$. Flexural strength, mechanical properties and hardness of composites are indispensable factors to obtain a longevity of a restorative material (Czasch \& Ilie, 2013; Ilie \& Stark, 2015).

In a study aimed at evaluating the compressive strength between single-increment resins, Rosatto et al. (2015) prepared 75 healthy human molars, where class II cavities were made $4 \mathrm{~mm}$ deep on the occlusal surface and $1 \mathrm{~mm}$ deep proximal. The compression test was carried out, where the study concluded that the high viscosity single-fill resins had inferior mechanical properties compared to the low viscosity and conventional resins. However, all Bulk-Fill composites had less polymerization shrinkage compared to conventional ones.

Alkhudhairy \& Vohra (2016) evaluated the compressive strength between three single-fill composites, these being Zircon Core (ZC), Multic Core Flow (MC) and Luxacore Dual (LC). 76 diskshaped samples were prepared, where half of the samples of each material were subjected to compressive forces until failure after one hour of photoactivation, and the other half after seven days. It was observed that the compressive strength between the three materials was significantly higher at seven days when compared to one hour. In addition, the $Z C$ resin contained zirconia in its composition and showed better results in terms of compressive strength than MC and LC resins that did not contain zirconia. Reinforcing the idea that zirconia is a material with excellent mechanical properties, high biocompatibility and durable.

In order to evaluate five single-fill resins, Tetric $\mathrm{N}$-ceram, SDR, Activa, Ketac Universal Aplicap and GC Fuji II, in relation to the diametrical tensionstrength (DTS), the test was carried out under compression load at a speed of $1.0 \mathrm{~mm} / \mathrm{min}$. In the results, the resins $\mathrm{N}$ ceram, Activa and SDR obtained the highest flexural strength ( $p>0.05)$, and SDR obtained the greatest diametrical tension strength (Alrahlah, 2018).

Degree of Conversion. The success of a resin restoration is related to the degree of conversion, such as: adequate polymerization, concentration of polymerization initiator, intensity and wavelength of the light source, shade and translucency of the material, size of the filler particles, properties improved physics, and more. Thus, the degree of conversion assesses the efficiency of light curing unit, made by spectroscopic techniques (Tarle et al., 2015).

Polymerization is influenced by the type of monomer, as well as the mechanical properties, where the wear resistance of the resin surface can be verified and its clinical performance is largely related to the degree of polymerization of the composites. Flexural and compression strength are measured by the fracture resistance of the restoration (Goracci et al., 2014; Alrahlah).

In the study by Tauböck et al. (2019) evaluated the contraction force, degree of conversion and the polymerization shrinkage of single-fill resins based on high and low viscosity dimethacrylate and Ormocer. Two flowable resins (SDR, X-tra base), two of high viscosity (Ormocer mass, SonicFill) and two conventional resins (Esthet X, X Esthet HD flux), were photoactivated for $20 \mathrm{~s}$ at $1.275 \mathrm{~mW} / \mathrm{cm}^{2}$. The resins of high viscosity showed significantly lower polymerization shrinkage and contraction strength, where Ormocer-based resin achieved great results. The single-filler with high viscosity resulted in less polymerization and strength shrinkage. Among the tested flow composite materials, SDR generated the lowest shrinkage force during polymerization and reached a significantly higher degree of conversion. Bulk-Fill resins developed less shrinkage forces than conventional flows in contrast to high-flow resins.

In order to evaluate the degree of conversion and hardness between two composite resins, Abed et 
MATOS, J. D. M.; NAKANO, L. J. N.; LOPES, G. R. S.; BOTTINO, M. A.; VASCONCELOS, J. E. L.; JESUS, R. H. \& MACIEL, L. C. Characterization of bulk-fill resin composites in terms of physical,chemical, mechanical and optical properties and clinical behavior. Int. J. Odontostomat., 15(1):226-233, 2021.

al. (2015) used Bulk-Fill X-tra fil resin (Voco) and Grandio conventional resin (Voco), where twenty five cylindrical samples $(5 \times 4 \mathrm{~mm})$ were made with the Teflon material mold, where it was filled with a single increment for Bulk Fill composites and two increments ( $2 \mathrm{~mm}$ each) for conventional. The molds were placed on a glass plate $(10 \mathrm{~mm})$ and another glass plate was placed on the molds. Each sample was light-cured according to the manufacturer's instructions, the samples were stored in a dry and dark environment, at room temperature for 24 hours before the test. The degree of conversion (DC) was determined using infrared spectroscopy, and the microhardness test was used to measure Vickers hardness (VHN) on the upper and lower surfaces of each specimen. The data for degree of conversion and hardness of vickers were analyzed by ANOVA and paired Newmanekeuls test. Thus, they concluded that $\mathrm{X}$-tra fil showed the highest DC performance and the differences in DC and VHN values between materials proved to be material dependent $(P<0.0001)$.

Tarle et al. evaluated the influence of irradiation time on the degree of conversion and the microhardness of Bulk-Fill resins (TetricEvoCeram Bulk Fill-TECBF; $x$-tra fil-XF; QuixFil-QF; SonicFill-SF) high viscosity and a conventional resin composite (TetricEvoCeram - TCE), where they were polymerized for 10,20 and 30 s at $1,170 \mathrm{~mW} / \mathrm{cm}^{2}$ and at five depths: $0,1,2,3,4,5$ and $6 \mathrm{~mm}$. The samples were stored in a dark environment $\left(37^{\circ} \mathrm{C}\right)$. After $24 \mathrm{~h}$ the degree of conversion and Knoopmicrohardness were recorded. They were statistically analyzed using ANOVA and Bonferroni 's post-hoc test $(a=0.05)$. With the increase in the polymerization time, the degree of conversion and the Knoopmicrohardness in deeper layers of the composites increased. The polymerization of 20 and $30 \mathrm{~s}$ at a depth of up to $4 \mathrm{~mm}$ had good results regardless of the material used in this study.

Polymerization Time. The translucency of the material can impair aesthetics, but allows the light to penetrate more deeply into the resin layers, thus improving the polymerization depth and the degree of conversion (llie, 2019). Complete polymerization is an important factor in light-curing composites, and this is still considered a challenge for dental surgeons in clinical practice. Correct polymerization requires a photoactivator emitting light source emitted by diodes (LED), with a light intensity of $400-500 \mathrm{~mW} / \mathrm{cm}^{2}$, but a light emitter of $200-600 \mathrm{~mW} / \mathrm{cm}^{2}$, in a correct exposure time it is still considered satisfactory to achieve polymerization (Alkhudhairy, 2017).
Polymerization requires a component called a photoinitiator that is an initiator molecule, the most used of which is camphorquinone. Some manufacturers have added a new initiator, Ivocerin, in their composites, which has a photopolymerization activity superior to camphorquinone, due to its greater absorption of visible light (Bucuta \& Ilie, 2014; Gomes et al., 2018; Pereira et al., 2018; Rizzante et al., 2019).

Farahat et al. (2016) evaluated the effect of irradiation time and material thickness by the degree of polymerization of a universal resin (Tetric N Ceram Universal) and Bulk-Fill (Tetric N Ceram filler), where the samples were made in teflon molds with a diameter of $5 \mathrm{~mm}$ and a height of 2, 4 and $6 \mathrm{~mm}$ in a total of 96 samples divided into 12 groups $(n=8)$. They used a LED light curing unit (Demi Kerr- USA) with an intensity of $1,000 \mathrm{~mW} / \mathrm{cm}^{2}$, where half of the samples were light-cured for 20 s and the other half for $40 \mathrm{~s}$. In the test, they were analyzed with a significance level of 5 $\%$. This study stated that the degree of conversion of Bulk-FillTetric N Ceram is higher than the universal type, both for the values of the irradiation time and the thickness of the material.

Alkhudhairy conducted a study in order to evaluate the effects of two light intensities $(1200 \mathrm{~mW}$ and $650 \mathrm{~mW}$ ) of hardening on the mechanical properties (Vickers microhardness, compressive strength and diametral tensile strength). Four BulkFill resins Tetric ${ }^{\circledR}$ N-Ceram, SonicFill, SDR, Filtek were tested. All tests were performed at a significance level of $p<0.05$. Seventy-two cylindrical samples from each group $(n=288)$ were prepared and submitted for each test $(n=12)$. The study showed that the highest microhardness was found for SonicFill (58.3 $\mathrm{MPa}$ ) when using a light intensity of $1200 \mathrm{~mW}$. There was a significant difference between SDR with low and high light intensity $(p<0.005)$. SonicFill also showed better compressive strength of (262.6 MPa), followed by SDR with (253.2 MPa), both being polymerized using a high-intensity light. The lowest compressive strength was found in the Tetric $\mathrm{N}$ Ceram of (214.3 MPa), using a low light intensity. Regarding the diametral tensile strength, all groups except SonicFill, using $1200 \mathrm{~mW}$ and $650 \mathrm{~mW}$, was significant $(p<0.001)$.

Karacolak et al. (2018) measured the radiant energy and the microhardness of six Bulk-Fill restorative resin composites (Aura, Filtek Bulk Fill Posterior, SonicFill, X-tra Fill, TetricEvoCeramBulk Fill, Admira Fusion X-tra), four Bulk Fill base resin 
MATOS, J. D. M.; NAKANO, L. J. N.; LOPES, G. R. S.; BOTTINO, M. A.; VASCONCELOS, J. E. L.; JESUS, R. H. \& MACIEL, L. C. Characterization of bulk-fill resin composites in terms of physical,chemical, mechanical and optical properties and clinical behavior. Int. J. Odontostomat., 15(1):226-233, 2021.

composites (Filtek Bulk Fill Flowabl, SDR, X-tra Base, Venus Bulk Fill) and one conventional resin composite (Z100). The samples were prepared according to the manufacturer's recommendations, thus, some materials were polymerized up to 5 or even $6 \mathrm{~mm}$ (Aura, SonicFill, FiltekBulk FillFlowab). Five samples were taken for each group and placed over a sensor of a visible light spectrophotometer and photopolymerized for 20 s and the light guide tip was positioned $1 \mathrm{~mm}$ above the samples and stored in distilled water at $37^{\circ} \mathrm{C}$ over a period of 24 hours before Knoopmicrohardness measurements. In the hardness test, each material was measured three times at both the top and bottom of the samples. The paired t-test and all statistical analyzes were used ( $p$ $<0.05$ ). In all groups, radiant energies decreased with increasing thickness. No significant difference was found between the top and bottom of the X-tra Fil 2 and $4 \mathrm{~mm}$, SDR 2 and $4 \mathrm{~mm}$ and X-tra Base $2 \mathrm{~mm}$ composites of the Aura $2 \mathrm{~mm}$ group. There was also no significant difference in the microhardness of thicknesses 2 and $4 \mathrm{~mm}$, for the bottom levels of the Aura, X-tra Fil, FiltekBulk Fill Posterior, SDR and Xtra Base composites. In the radiant energy groups, microhardness was affected in the composites X-tra Fil, TetricEvoCeramBulk-Fill, FiltekBulk FillFlowabl and Z100.

Lima et al. (2018) performed a systematic review where they analyzed the polymerization depth of Bulk-Fill resins, and obtained as results that the time of 20s, in an irradiance between 700 and $800 \mathrm{Mw}$ $/ \mathrm{cm} \sum$, is reached about $16 \mathrm{~J} / \mathrm{cm} \sum$, in $2 \mathrm{~mm}$ increments in conventional composite resins, whereas Bulk-Fill resins, in a polymerization of 20 s, with irradiance $>1000 \mathrm{Mw} / \mathrm{cm} \sum$, reach $20 \mathrm{~J}$, considering the ideal dose for polymerization of $4 \mathrm{~mm}$ increments of these composites.

Polymerization shrinkage. For the use of larger increments of Bulk-Fill resins, the manufacturers claim that the molecular base has been altered, reducing or even replacing Bis-GMA with a lower viscosity monomer, and / or using higher molecular weight monomers, such as, Bis-EMA (Bisphenol-A-glycidyl methacrylate), TEGDMA (triethylene glycol dimethacrylate), EBPDMA (Ethyl 4-dimethyl aminobenzoate) and UDMA (Diurethanedimethacrylate). In addition, the incorporation of stress-relieving materials and changes in the filler content of these composites also help to control the polymerization contraction. There may be a variation of 1.8 to $3.3 \%$ of the initial total volume of the material inserted in the cavity, after light-curing (Al
Shaafi et al., 2011; et al., 2015; Fronza et al., 2017; Almeida Junior et al., 2018; Rizzante et al.; Yao et al., 2020a,b).

In order to evaluate the Vickers microhardness and the polymerization depth of two Bulk-Fill composite resins (X-tra Fil, Voco; Sonic-FillTM 2, Kerr Corporation) and an conventional resin composite (Filtek TM Z250 XT, 3M ESPE), Moharam et al. (2017) prepared sixty cylindrical samples of $4 \mathrm{~mm}$ thickness using Teflon molds. The specimens were divided into six groups ( $\mathrm{n}$ $=10$ ) according to the type of material used and according to the insertion technique applied. The prepared specimens were stored dry, in a dark environment at $37^{\circ} \mathrm{C}$ for 24 hours. The authors observed a significant difference in Vickers microhardness and in the polymerization depth values between the tested materials, with X-tra Fil presenting the highest values of Vickers surface microhardness. Both composite resins showed greater depth of polymerization for both insertion techniques.

In the study by Gonçalves et al. (2018) the degree of conversion of eight resins was evaluated, two conventional (Filtek Z350 XT (Z350), 3M ESPE, Filtek Z350 XT flowable (ZF), 3M ESPE) and five BulkFill (everX Posterior (EP), GC Europe, SonicFill (SF), Kerr, Filtek Bulk Fill Posterior (FBP), 3M ESPE, FiltekBulk Fill Flow (FBF), 3M ESPE, Venus Bulk Fill Flow (VB), Heraeus). The degree of conversion was determined by FTIR spectroscopy. The data were submitted to the one-way ANOVA and Tukey test (a $=0.05)$. Bulk-Fill resins exhibited similar or less volumetric shrinkage (1.4 to $0,4 \%)$ than conventional composites (1.7-2.1\%), however, only four of the single-increment composites were able to sustain a homogeneous conversion at a depth of $4 \mathrm{~mm}$.

Clinical Behavior. Despite the extensive improvements made, the resin shrinkage with polymerization remains a major disadvantage in the clinic, which can promote the detachment between restorations and the tooth, leading to the development of postoperative sensitivity, micro leakage, secondary caries and failure of the restoration. Proper material selection can be essential for clinical success. Several alternatives have been proposed in the literature to reduce polymerization shrinkage, such as alternative methods of light-curing, low irradiance, and the use of incremental filling techniques, which has been completely incorporated into clinical practice (Tsujimoto et al., 2017; Gonçalves et al.; Romão et al., 2018; Peixoto et al., 2019). 
Bulk-Fill resins have a short activation time due to the presence of modified initiation systems, which reduce polymerization shrinkage and increase translucency, allowing light to pass through the material. This high translucency becomes a disadvantage in terms of the aesthetics of the material, which facilitates its use in a single increment without the need for any leveling or coverage. In addition, they have a high capacity to resist wear, and the use of a greater increment helps to reach the satisfactory proximal contact. Due to their high inorganic content, they can be used in areas of great masticatory effort (International Organization for Standardization, 2009; Monterubbianesi et al., 2016; Shibasaki et al., 2017; Son et al., 2017; Van Ende et al., 2017; Shimokawa et al., 2018; Kebler et al., 2019; Veloso et al., 2019).

In order to evaluate the Class I internal marginal adaptation of Bulk Fill resin and a conventional resin, Furness et al. (2014) prepared 50 molars with $4 \mathrm{~mm}$ cavities, and restored using Bulk-Fill resins (SureFil SDRFlow ( SDR), Quixx, SonicFill, TetricEvoCeram Bulk) and a conventional composite for $2 \mathrm{~mm}$ increments (Filtek Supreme Ultra). The polymerization time occurred according to the manufacturer's recommendations. Teeth were sectioned occluso-gingivally and dye was placed on the internal margin and visually examined by 3 observers. It was possible to conclude that percentage of gap-free margins was significantly lower at the pulpal floor interface than at the enamel interface, except for SDR. The use of a Bulk-Fill restorative material compared to a conventional composite resulted in a similar proportion of internal marginal interface without gaps in the middle dentin and enamel areas.

\section{CONCLUSION}

It can be concluded from this study that: BulkFill resins have characteristics similar to traditional composite resins, when performed according the usage protocol. With the use of this group of resins in a single increment, it is possible to eliminate the step of several increments, in turn decreasing the clinical time. In addition, possible failures that occur during the restorative procedure can be minimized, such as: less chance of incorporating bubbles and a volumetric contraction with less stress on the interface. Even though it is a new restorative material, Bulk-Fill resins have excellent results, thus being easy to use due to greater flow providing ease of handling, in turn, reducing the time of clinical restorative procedures and with an excellent cost benefit. However, it should be noted that this class of resins did not arise with the intention of replacing conventional resins, but to be an option of restorative material, being indicated in specific cases. In addition, more studies are needed to obtain a greater compression of the subject studied in this research.

MATOS, J. D. M.; NAKANO, L. J. N.; LOPES, G. R. S.; BOTTINO, M. A.; VASCONCELOS, J. E. L.; JESUS, R. H. \& MACIEL, L. C. Caracterización de resina compuesta mono incremental en relación a las propiedades físicas, químicas, mecánicas y ópticas y el comportamiento clínico. Int. J. Odontostomat., 15(1):226-233, 2021.

RESUMEN: Este estudio tuvo como objetivo evaluar las propiedades físicas, químicas, mecánicas y ópticas de la resina Bulk-Fill, en relación con la literatura y sus usos clínicos apropiados. Realizamos una búsqueda bibliográfica en las bases de datos de salud PUBMED (www.pubmed.gov) y Scholar Google (www.scholar.google.com.br), en la que se recopilaron trabajos que se publicaron entre 1994 y 2020 . Fueron incluidos estudios de laboratorio, informes de casos, revisiones sistemáticas y revisiones de literatura, desarrollados en individuos vivos. Por tanto, se excluyeron los artículos que no trataban las características de la resina Bulk-Fill y sus usos clínicos adecuados. El uso de la resina Bulk-Fill ha ido aumentando progresivamente a lo largo de los años, presentando buenas propiedades, logrando éxito en el rendimiento clínico, facilidad de manejo y, por lo tanto, se ha convertido en el material elegido por los dentistas. Además, su longevidad demuestra durabilidad, con propiedades mecánicas y resistencia a la estructura dental.Las resinas Bulk-Fill tienen características similares a las resinas compuestas tradicionales, cuando se realizan siguiendo el protocolo de uso. Con el uso de este grupo de resinas mono incremental, es posible eliminar el paso de varios incrementos, disminuyendo a su vez el tiempo clínico. Además, se pueden minimizar las posibles fallas que se producen durante el procedimiento de restauración, tales como: menos posibilidades de incorporar burbujas y una contracción volumétrica con menos estrés en la interfaz.

PALABRAS CLAVE: resinas compuestas, estrés mecánico, propiedades físicas, estética dental.

\section{REFERENCES}

Abed, Y. A.; Sabry, H. A. \& Alrobeigy, N. A. Degree of conversion and surface hardness of bulk-fill composite versus incrementalfill composite. Tanta Dent J., 12(2):71-80, 2015.

Al Shaafi, M.; Maawadh, A. \& Al Qahtani, M. Evaluation of light intensity output of QTH and LED curing devices in various governmental health institutions. Oper. Dent., 36(4):356-61, 2011. 
Alkhudhairy, F. \& Vohra, F. Compressive strength and the effect of duration after photo-activation among dual-cure bulk fill composite core materials. Pak. J. Med. Sci., 32(5):1199-203, 2016.

Alkhudhairy, F. I. The effect of curing intensity on mechanical properties of different bulk-fill composite resins. Clin. Cosmet. Investig. Dent., 9:1-6, 2017.

Almeida Junior, L. J. D. S.; Lula, E. C. O.; Penha, K. J. S.; Correia, V. S.; Magalhães, F. A. C.; Lima, D. M. \& Firoozmand, L. M. Polymerization shrinkage of bulk fill composites and its correlation with bond strength. Braz Dent J., 29(3):261-67, 2018.

Alrahlah, A. Diametral tensile strength, flexural strength, and surface microhardness of bioactive bulk fill restorative. J. Contemp. Dent. Pract., 1;19(1):13-9, 2018.

Boaro, L. C.; Gonçalves, F.; Guimarães, T. C.; Ferracane, J. L.; Versluis, A. \& Braga, R. R. Polymerization stress, shrinkage and elastic modulus of current low-shrinkage restorative composites. Dent. Mater., 26(12):1144-50, 2010.

Bucuta, S. \& Ilie, N. Light transmittance and micro-mechanical properties of bulk fill vs. conventional resin based composites. Clin. Oral Investig., 18(8):1991-2000, 2014.

Chen, Y.; Li, H. \& Fok, A. In vitro validation of a shape-optimized fiber-reinforced dental bridge. Dent. Mater., 27(12):1229-37, 2011.

Chesterman, J.; Jowett, A.; Gallacher, A. \& Nixon, P. Bulk-fill resinbased composite restorative materials: a review. Br. Dent. J., 222(5):337-44, 2017.

Czasch, P. \& Ilie, N. In vitro comparison of mechanical properties and degree of cure of bulk fill composites. Clin. Oral Investig., 17(1):22735, 2013.

El-Damanhoury, H. \& Platt, J. Polymerization shrinkage stress kinetics and related properties of bulk-fill resin composites. Oper. Dent., 39(4):374-82, 2014

Farahat, F.; Daneshkazemi, A. R. \& Hajiahmadi, Z. The effect of bulk depth and irradiation time on the surface hardness and degree of cure of bulk-fill composites. J. Dent. Biomater., 3(3):284-91, 2016.

Fronza, B. M.; Ayres, A.; Pacheco, R. R.; Rueggeberg, F. A.; Dias, C. \& Giannini, M. Characterization of Inorganic Filler Content, Mechanical Properties, and Light Transmission of Bulk-fill Resin Composites. Oper. Dent. 42(4):445-55, 2017.

Furness, A.; Tadros, M. Y.; Looney, S. W. \& Rueggeberg, F. A. Effect of bulk/incremental fill on internal gap formation of bulk-fill composites. J. Dent., 42(4):439-49, 2014.

Gomes, T. N.; Matos, J. D. M.; Vasconcelos, J. E. L.; Olivieri, K. A. N.; Brandt, W. C. \& Miranda, M. E. Effect of different photoiniciers of experimental adhesive systems on adhesive interface union resistance. Int. Arch. Med., 11(26):1-12, 2018.

Gonçalves, F.; Campos, L. M. P.; Rodrigues-Júnior, E. C.; Costa, F. V.; Marques, P. A.; Francci, C. E.; Braga, R. R. \& Boaro, L. C. C. A comparative study of bulk-fill composites: degree of conversion, post-gel shrinkage and cytotoxicity. Braz. Oral Res., 32:e17, 2018.

Goracci, C.; Cadenaro, M.; Fontanive, L.; Giangrosso, G.; Juloski, J.; Vichi, A. \& Ferrari, M. Polymerization efficiency and flexural strength of low-stress restorative composites. Dent. Mater., 30(6):688-94, 2014

Ilie, N. \& Hickel, R. Investigations on a methacrylate-based flowable composite based on the SDR ${ }^{\mathrm{TM}}$ technology. Dent. Mater., 27(4):348-55, 2011.

Ilie, N. \& Stark, K. Effect of different curing protocols on the mechanical properties of low-viscosity bulk-fill composites. Clin. Oral Investig., 19(2):271-9, 2015.

Ilie, N. Sufficiency of curing in high-viscosity bulk-fill resin composites with enhanced opacity. Clin. Oral Investig., 23(2):747-55, 2019.

International Organization for Standardization. ISO 4049. Polymer Based Filling Restorative and Luting Materials. 3rd ed. Geneva, International Organization forStandardization, 2009. p.1-27. Available from: https://www.iso.org/standard/42898.html.
Karacolak, G.; Turkun, L. S.; Boyacioglu, H. \& Ferracane, J. L. Influence of increment thickness on radiant energy and microhardness of bulk-fill resin composites. Dent. Mater. J., 37(2):206-13, 2018.

Kebler, A.; Kaisarly, D.; Hickel, R. \& Kunzelmann, K. H. Effect of fiber incorporation on the contraction stress of composite materials. Clin. Oral Investig., 23(3):1461-71, 2019.

Labella, R.; Lambrechts, P.; Van Meerbeek, B. \& Vanherle, G. Polymerization shrinkage and elasticity of flowable composites and filled adhesives. Dent. Mater., 15(2):128-37, 1999.

Lima, R. B. W.; Troconis, C. C. M.; Moreno, M. B. P.; Murillo-Gómez, F. \& De Goes, M. F. Depth of cure of bulk fill resin composites: A systematic review. J. Esthet. Restor. Dent., 30(6):492-501, 2018.

Lin, F.; Josephs, S. F.; Alexandrescu, D. T.; Ramos, F.; Bogin, V.; Gammill, V.; Dasanu, C. A.; De Necochea-Campion, R.; Patel, A. N.; Carrier, E.; et al. Lasers, stem cells, and COPD. J. Transl. Med., 8:16, 2010

Moharam, L. M.; El-Hoshy, A. Z. \& Abou-Elenein, K. The effect of different insertion techniques on the depth of cure and vickers surface micro-hardness of two bulk-fill resin composite materials. J. Clin. Exp. Dent., 9(2):e266-71, 2017.

Monterubbianesi, R.; Orsini, G.; Tosi, G.; Conti, C.; Librando, V.; Procaccini, M. \& Putignano, A. Spectroscopic and mechanical properties of a new generation of bulk fill composites. Front. Physiol., 7:652, 2016.

Nascimento, A. S.; Rodrigues, J. F. B.; Torres, R. H. N.; Santos, K. O.; Fook, M. V. L.; Albuquerque, M. S.; Lima, E. A.; Filgueira, P. T. D.; Santos, J. B. M. D.; Oliveira, L. J. R.; et al. Physicomechanical and thermal analysis of bulk-fill and conventional composites. Braz. Oral Res., 33:e008, 2019.

Peixoto, N. M.; de-Matos, J. D. M.; Andrade, V. C.; Bottino, M. A. \& Zogheib, L. V. Evaluation of union resistance of orthodontic bracelets fixed to lithium dissylate ceramic. Int. J. Odontostomat., 13(2):207-18, 2019.

Pereira, A. L. C.; Matuda, L. S. A.; Lima, L. G.; Silva, M. F. L.; MoraisSousa, L. K.; Matos, J. D. M.; Vasconcelos, J. E. L. \& Medeiros, C. R. Evaluation of thefluorescence of composite resins under an ultra violet light source. Int. J. Odontostomat., 12(3):252-61, 2018.

Reis, A. F.; Vestphal, M.; Amaral, R. C. D.; Rodrigues, J. A.; Roulet, J. F. \& Roscoe, M. G. Efficiency of polymerization of bulk-fill composite resins: a systematic review. Braz. Oral Res., 31(1):e59, 2017.

Rizzante, F. A. P.; Duque, J. A.; Duarte, M. A. H.; Mondelli, R. F. L.; Mendonça, G. \& Ishikiriama, S. K. Polymerization shrinkage, microhardness and depth of cure of bulk fill resin composites. Dent. Mater. J., 1;38(3):403-10, 2019.

Romão, R. M.; Lopes, G. R. S.; Matos, J. D. M.; Lopes, G. R. S.; Vasconcelos, J. E. L. \& Fontes, N. M. Causes of failures in ceramic veneers restorations: A literature review. Int. J. Adv. Res., 6(4):896-906, 2018.

Rosatto, C. M.; Bicalho, A. A.; Veríssimo, C.; Bragança, G. F.; Rodrigues, M. P.; Tantbirojn, D.; Versluis, A. \& Soares, C. J. Mechanical properties, shrinkage stress, cuspal strain and fracture resistance of molars restored with bulk-fill composites and incremental filling technique. J. Dent., 43(12):1519-28, 2015.

Rueggeberg, F. A.; Caughman, W. F. \& Curtis, J. W. Effect of light intensity and exposure duration on cure of resin composite. Oper. Dent., 19(1):26-32, 1994

Shibasaki, S.; Takamizawa, T.; Nojiri, K.; Imai, A.; Tsujimoto, A.; Endo, H.; Suzuki, S.; Suda, S.; Barkmeier, W. W.; Latta, M. A.; et al. Polymerization Behavior and Mechanical Properties of HighViscosity Bulk Fill and Low Shrinkage Resin Composites. Oper. Dent., 42(6):E177-87, 2017.

Shimokawa, C. A. K.; Turbino, M. L.; Giannini, M.; Braga, R. R. \& Price, R. B. Effect of light curing units on the polymerization of bulk fill resin-based composites. Dent. Mater., 34(8):1211-21, 2018. 
MATOS, J. D. M.; NAKANO, L. J. N.; LOPES, G. R. S.; BOTTINO, M. A.; VASCONCELOS, J. E. L.; JESUS, R. H. \& MACIEL, L. C. Characterization of bulk-fill resin composites in terms of physical,chemical, mechanical and optical properties and clinical behavior. Int. J. Odontostomat., 15(1):226-233, 2021.

Son, S. A.; Park, J. K.; Seo, D. G.; Ko, C. C. \& Kwon, Y. H. How light attenuation and filler content affect the microhardness and polymerization shrinkage and translucency of bulk-fill composites? Clin. Oral Investig., 21(2):559-65, 2017.

Stavridakis, M. M.; Kakaboura, A. I. \& Krejci, I. Degree of remaining $\mathrm{C}=\mathrm{C}$ bonds, polymerization shrinkage and stresses of dual-cured core build-up resin composites. Oper. Dent., 30(4):443-52, 2005.

Tarle, Z.; Attin, T.; Marovic, D.; Andermatt, L.; Ristic, M. \& Tauböck, T. T. Influence of irradiation time on subsurface degree of conversion and microhardness of high-viscosity bulk-fill resin composites. Clin. Oral Investig., 19(4):831-40, 2015.

Tauböck, T. T. \& Attin, T. Composites «Bulk Fill»: Une mise à jour. Swiss Dent. J., 126(9):812-3, 2016.

Tauböck, T. T.; Jäger, F. \& Attin, T. Polymerization shrinkage and shrinkage force kinetics of high- and low-viscosity dimethacrylateand ormocer-based bulk-fill resin composites. Odontology, 107(1):103-10, 2019.

Tsujimoto, A.; Barkmeier, W. W.; Takamizawa, T.; Latta, M. A. \& Miyazaki, M. Depth of cure, flexural properties and volumetric shrinkage of low and high viscosity bulk-fill giomers and resin composites. Dent. Mater. J., 36(2):205-13, 2017.

Van Ende, A.; De Munck, J.; Lise, D. P. \& Van Meerbeek, B. Bulk-fill composites: a review of the current literature. J. Adhes. Dent., 19(2):95-109, 2017.

Veloso, S. R. M.; Lemos, C. A. A.; de Moraes, S. L. D.; do Egito Vasconcelos, B. C.; Pellizzer, E. P. \& de Melo Monteiro, G. Q. Clinical performance of bulk-fill and conventional resin composite restorations in posterior teeth: a systematic review and metaanalysis. Clin. Oral Investig., 23(1):221-33, 2019.

Yao, C.; Ahmed, M. H.; Okazaki, Y.; Van Landuyt, K. L.; Huang, C. \& Van Meerbeek, B. Bonding efficacy of a new self-adhesive restorative onto flat dentin vs class-i cavity-bottom dentin. J. Adhes. Dent., 22(1):65-77, 2020a.

Yao, C.; Ahmed, M. H.; Zhang, F.; Mercelis, B.; Van Landuyt, K. L.; Huang, C. \& Van Meerbeek, B. Structural/chemical characterization and bond strength of a new self-adhesive bulkfill restorative. J. Adhes. Dent., 22(1):85-97, 2020b.

Zorzin, J.; Maier, E.; Harre, S.; Fey, T.; Belli, R.; Lohbauer, U.; Petschelt, A. \& Taschner, M. Bulk-fill resin composites: polymerization properties and extended light curing. Dent. Mater., 31(3):293-301, 2015.
Corresponding author:

Jefferson David Melo de Matos

Department of Dental Materials and Prosthodontics

São Paulo State University (Unesp)

Institute of Science and Technology

Email: matosjefferson19@gmail.com

ORCID: https://orcid.org/0000-0003-4507-0785 